\title{
Administration of analgesics in patients with acute abdominal pain: a survey of the practice of doctors in a developing country
}

\author{
Babatunde A. Ayoade • Adedayo O. Tade • \\ Babatunde A. Salami • Olayemi Oladapo
}

Received: 21 February 2009 / Accepted: 13 June 2009 / Published online: 1 September 2009

(C) Springer-Verlag London Ltd 2009

\begin{abstract}
Background Analgesic use, particularly opioids in the emergency situation in patients with acute abdominal pain, generally has been avoided in the past; however, newer evidence has shown that the practice should be encouraged. In spite of this, many physicians still withhold analgesics in this clinical situation.

Aims The aim of the study was to evaluate the current opinion and practice of Nigerian doctors regarding the use of analgesics for patients with acute abdominal pain during the initial evaluation.

Methods A one-page survey was distributed by two of the authors to Nigerian doctors from different parts of the country during conferences, seminars and meetings on different occasions in 2007. Demographic data and information regarding medical specialty, post-qualification experience, analgesic use in acute abdominal pain, and effects on diagnosis and outcome were included. The respondents were then classed into two sets of two groups using specialty (surgical and non-surgical) and post-qualification experience (less than 10 years, "less experienced;" over 10 years, "experienced"). Results There were 539 respondents. The male:female ratio was 12:1. Of the respondents, $50.4 \%$ would withhold
\end{abstract}

The views expressed in this paper are those of the author(s) and not those of the editors, editorial board or publisher.

B. A. Ayoade $(\bowtie) \cdot$ A. O. Tade $\cdot$ B. A. Salami

Department of Surgery,

Olabisi Onabanjo University Teaching Hospital,

P.O.Box 17, Sagamu, Ogun State, Nigeria

e-mail: teruayoade@yahoo.co.uk

O. Oladapo

Department of Obstetrics and Gynecology,

University College Hospital,

Ibadan, Oyo State, Nigeria analgesics if the diagnosis was unclear, and a further $12 \%$ would do the same if a surgical opinion was required. Reasons for withholding analgesics were (1) believing that analgesics interfered with evolution of signs $(84.4 \%)$, (2) believing that the diagnosis would be impaired (77.9\%) and (3) believing that analgesics would have an adverse effect on outcome $(54.5 \%)$. Specialty or length of post-qualification experience did not significantly influence this practice $(\mathrm{p}<0.05)$.

Conclusion The study has shown that the dogma that analgesics are harmful in patients with acute abdominal pain is still firmly entrenched in the practice of the surveyed Nigerian doctors. This belief is not significantly affected by specialty or post-qualification experience.

Keywords Acute abdominal pain · Analgesics · Doctors

\section{Introduction}

In the past, it was customary to withhold analgesia, particularly opioids, in patients with acute abdominal pains prior to establishment of a definitive diagnosis. Analgesics were thought to interfere with diagnosis by masking the evolution of symptoms and signs with a subsequent delay in surgical treatment [1]. The dogma was popularized by Cope's "Early Diagnosis of the Acute Abdomen," first published in 1926, and this dogma may have been valid at that time in the absence of sophisticated diagnostic facilities and also because of the traditional use of large doses of morphine.

This approach, which is not evidence based, has been challenged by numerous studies in the last decade [2-8]. These studies have demonstrated a significant reduction of pain at the time of initial assessment without interfering with diagnostic accuracy. A more recent edition of Cope's "Early Diagnosis of the Acute Abdomen" suggests that 
withholding analgesics is a cruel practice that should be condemned [9].

Despite this growing evidence of the usefulness of analgesia in such clinical situations, there is still reluctance on the part of many physicians to prescribe analgesia in these cases [10-13].

Emergency medicine as a speciality is still in a rudimentary state of development in many countries in the developing world. Patients with acute abdominal symptoms are first seen mostly by general medical practitioners and casualty officers in the emergency rooms in these countries. In light of this, it is imperative to bring to attention issues that will enhance patient care by this group of physicians regarding the management of acute abdominal pain in the clinical setting in developing countries.

For this reason, a survey was carried out to evaluate the current opinion and practice of Nigerian doctors regarding the use of analgesics in patients with acute abdominal pain during the initial evaluation.

\section{Methodology}

A one-page survey was distributed to Nigerian doctors by two of the authors on different occasions and at different locations in the country where there were assemblies of Nigerian doctors from different parts of the country, such as conferences, seminars and professional association meetings, in 2007. The surveys were collected on the spot. Demographic data such as age, sex, qualification, specialty, post-qualification experience in years, level of practice and analgesia policy of the respondents' institutions were requested.

The survey included information regarding analgesic use in acute abdominal pain, such as the average number of patients with abdominal pain seen per year, the type of analgesic prescribed, when analgesics were prescribed and the reason to withhold analgesics, if any. Also the effect of analgesics on the evolution of signs, diagnostic accuracy and outcome were surveyed.

Table 1 Some characteristics of respondents

\begin{tabular}{lll}
\hline Specialty & & \\
\hline Surgical specialty & 245 & $45.5 \%$ \\
Surgery & 133 & $24.7 \%$ \\
Gynecology and obstetrics & 122 & $20.8 \%$ \\
Others & 105 & $19.5 \%$ \\
None & 189 & $35.1 \%$ \\
Level of practice & & \\
Primary care & 14 & $2.6 \%$ \\
Secondary care & 35 & $6.5 \%$ \\
Tertiary care & 490 & $90.9 \%$ \\
\hline
\end{tabular}

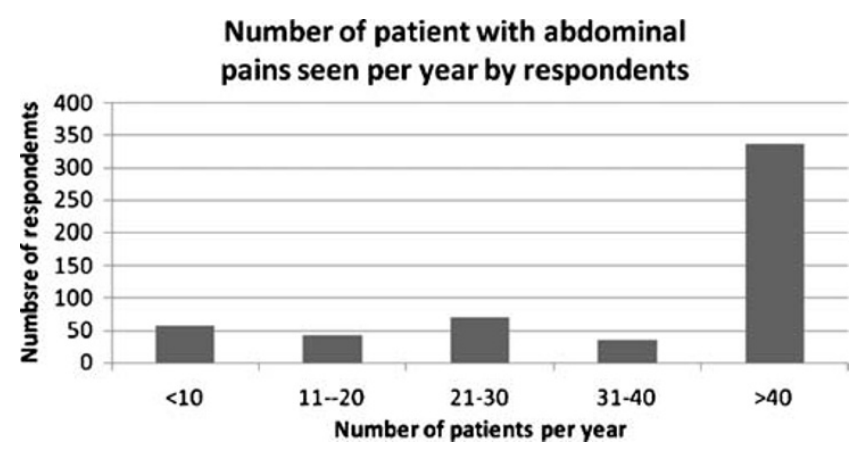

Fig. 1 Number of patients with abdominal pain seen per year by respondents

The respondents were divided into two groups based on post-qualification experience: "less experienced" and "experienced." The respondents with less than 10 years' postqualification experience were classified as "less experienced." Those with more than 10 years' post-qualification experience were classified as "experienced." The respondents were classed into another two groups based on whether they were in a surgical specialty. Those in a surgical specialty, including gynecology, were classed as "surgeons," and those who were in other specialties were classed as "non-surgeons."

Doctors with less than 2 years' post-qualification experience and those not in clinical practice were excluded.

Epi Info 2003 statistical software was used to analyze the results. Some of the results were expressed in percentages. Chi-square test was applied to the observed values in the "experienced" and "less experienced" groups, and also to the "surgeon" and "non-surgeon" groups. The significance level was set at $\mathrm{p}<0.05$.

\section{Analgesic type prescribed by respondents}

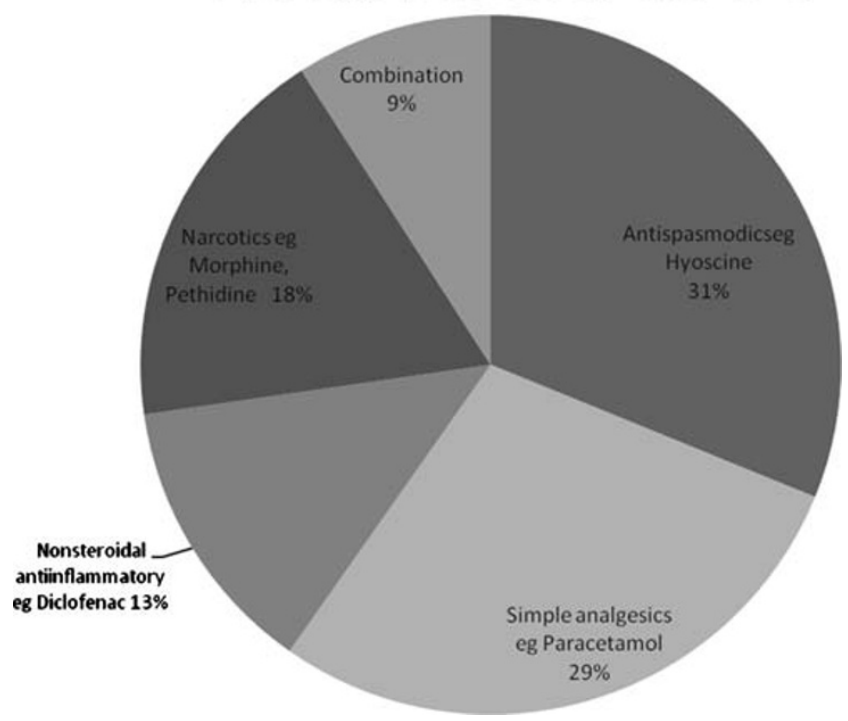

Fig. 2 Analgesic type prescribed by respondents 
Table 2 Respondents' views on analgesic interference with evolution of signs, effect on diagnosis and outcome

\begin{tabular}{lll}
\hline Interference with evolution of signs & & \\
\hline Yes & 455 & $84.4 \%$ \\
No & 84 & $15.6 \%$ \\
Effect on diagnosis & & \\
$\quad$ Enhance & 28 & $5.2 \%$ \\
Impair & 420 & $77.9 \%$ \\
No effect & 91 & $16.9 \%$ \\
Effect on outcome & & \\
Adverse effect & 294 & $54.5 \%$ \\
Beneficial & 112 & $20.8 \%$ \\
None & 133 & $24.7 \%$ \\
\hline
\end{tabular}

\section{Results}

A total of 562 surveys were distributed, of which 23 were excluded from the analysis because of incomplete data. The respondents were 497 males (92.5\%) and 42 females (7.5\%). The age range of the respondents was $28-57$ years, with a mean of 37.1 years and standard deviation of 7.15 years. Post-qualification experience in years ranged from 2 to 33 , with a mean of 10.7 and standard deviation of 7.44. Of the respondents, $294(54.5 \%)$ had less than 10 years' postqualification experience; 168 respondents $(31.2 \%)$ had postgraduate fellowship qualifications, $133(24.7 \%)$ were specialist or specialist in training in surgery, and $245(45.5 \%)$ were in a surgical specialty; 490 respondents $(90.9 \%)$ practiced at the tertiary care level (Table 1).

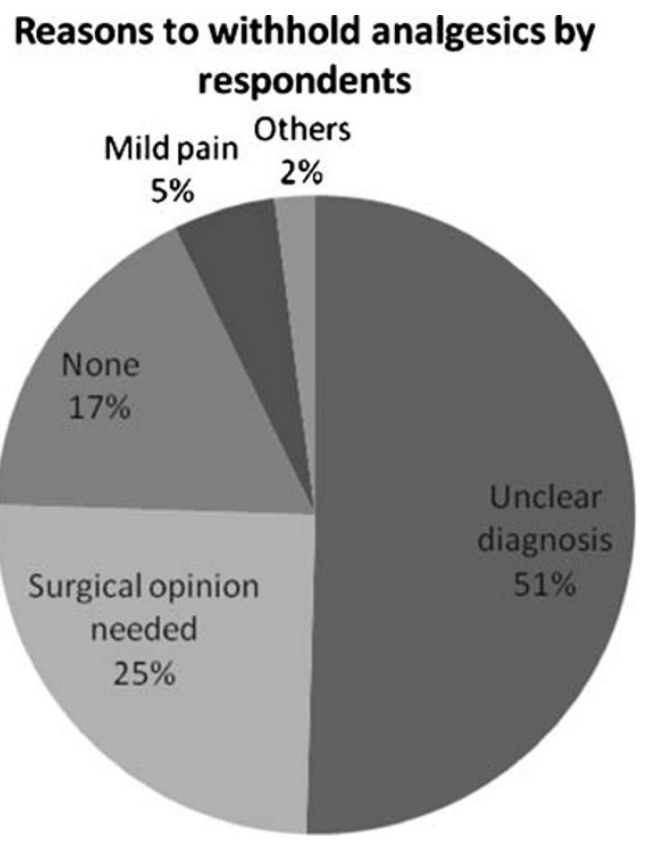

Fig. 3 Reasons to withhold analgesics by respondents
Table 3 Views of respondents regarding effects of analgesics on the evolution of signs, diagnosis and patient outcome

Interference with evolution of signs:

\begin{tabular}{lllll}
\hline Group: & Yes & & No & Total \\
Experienced & 266 & & 28 & 294 \\
Less experienced & 189 & & 56 & 245 \\
& 455 & & 84 & 539 \\
$\mathrm{X}^{2}=2.5798, \mathrm{p}>0.1$ & & & & \\
Effect on diagnosis: & & & No effect & Total \\
Group & Enhance & Impair & 49 & 294 \\
Experienced & 7 & 238 & 42 & 245 \\
Less experienced & 21 & 182 & 91 & 539 \\
& 28 & 420 & & \\
$\mathrm{X}^{2}=1.598, \mathrm{p}>0.4$ & & & & \\
Effect on outcome: & & & None & Total \\
Group & Adverse & Beneficial & 77 & 294 \\
Experienced & 147 & 70 & 56 & 245 \\
Less experienced & 147 & 42 & 133 & 539 \\
& 294 & 112 & & \\
$\mathrm{X}^{2}=0.8443, \mathrm{p}>0.6$ & & & & \\
\hline
\end{tabular}

Ninety-one respondents $(16.9 \%)$ practiced in institutions with an analgesic policy for use in abdominal pain; 336 respondents $(62.8 \%)$ saw more than 40 patients per year (Fig. 1). Analgesics prescribed included antispasmodics by 168 respondents $(31.2 \%)$ and simple analgesics by 154 respondents (28.6\%) (Fig. 2).

Four hundred fifty-five respondents (84.4\%) thought analgesics interfere with the evolution of signs, $420(77.9 \%)$

Table 4 Views of respondents regarding the effects of analgesics on evolution of signs, diagnosis and patient outcome

Interference with evolution of signs:

\begin{tabular}{|c|c|c|c|c|}
\hline Group: & \multicolumn{2}{|l|}{ Yes } & No & Total \\
\hline Surgeons & \multicolumn{2}{|l|}{189} & 56 & 245 \\
\hline Non-surgeons & \multicolumn{2}{|l|}{266} & 28 & 294 \\
\hline \multicolumn{5}{|c|}{$X^{2}=2.5798, p>0.1$} \\
\hline \multicolumn{5}{|c|}{ Effect on diagnosis: } \\
\hline Group & Enhance & Impair & No effect & Total \\
\hline Surgeons & 21 & 175 & 49 & 245 \\
\hline \multirow[t]{2}{*}{ Non-surgeons } & 7 & 245 & 42 & 294 \\
\hline & 28 & 42 & 91 & 539 \\
\hline \multicolumn{5}{|c|}{$X^{2}=2.1248, p>0.3$} \\
\hline \multicolumn{5}{|c|}{ Effect on outcome: } \\
\hline Group & Adverse & Beneficial & None & Total \\
\hline Surgeons & 112 & 77 & 56 & 245 \\
\hline \multirow[t]{2}{*}{ Non-surgeons } & 182 & 35 & 77 & 294 \\
\hline & 294 & 112 & 133 & 539 \\
\hline \multicolumn{5}{|c|}{$X^{2}=4.5055, p>0.1$} \\
\hline
\end{tabular}


felt they cause impairment of diagnosis, and 294 (54.5\%) thought they have adverse effects on outcome (Table 2).

Two hundred seventy-two respondents $(50.4 \%)$ would not administer analgesics if the diagnosis was unclear; 65 respondents $(12 \%)$ would not if a surgical opinion was required. Other reasons for withholding analgesics are presented in Fig. 3.

Two hundred sixty-six of 294 respondents in the "experienced" group thought analgesics interfere with the evolution of signs as compared with 189 of 245 respondents in the "less experienced" group. The findings regarding effects on diagnostic accuracy and outcome are shown in Table 3.

Of 245 respondents in the surgical group, 189 thought analgesics interfere with the evolution of signs, while 266 of 294 respondents in the non-surgical group thought the same. The views regarding the effect of analgesics on diagnostic accuracy and outcome as expressed by respondents in these groups are presented in Table 4.

\section{Discussion}

There are various impediments to the concept of analgesic use in patients with acute abdominal pain, and these include failure of the physician to appreciate the severity of pain as experienced by the patient [14] and fear of masking clinical signs causing a delay in diagnosis and definitive treatment. Other reasons put forward include alleged interference with the ability to give informed consent in the event of need for surgery, but this has been disputed by many studies [15-17].

In this study $90.9 \%$ of the respondents practiced at the tertiary care level. This may be due to the method of recruitment of respondents for this study, and moreover there seems to be a concentration of medical practitioners in these tertiary centers. Only $16.9 \%$ of the respondents practiced in institutions with a clear analgesic use policy for abdominal pain; this is similar to the findings of Zimmerman et al. in Israel [18].

Simple analgesics and antispasmodics were the more commonly prescribed medications by respondents in this study (59.8\%), and only $18.2 \%$ of respondents prescribed narcotics. Also $50.4 \%$ of the respondents would not prescribe analgesics if the diagnosis was not clear, and $25 \%$ would not if a surgical consultation was required. This is not surprising since the majority of the respondents $(84.5 \%)$ held the traditional view that analgesics interfere with the evolution of signs, therefore impairing diagnosis (77.9\%), and that analgesics have an adverse effect on outcome $(54.5 \%)$. These findings are essentially similar to the results of other surveys that show the reluctance of physicians to administer analgesics to patients with abdominal pain in the emergency situation [10-13]. This view was not substantially affected by the specialty of the respondents in this study or by the post-qualification experience as shown in Tables 3 and 4. Some studies have shown considerable reluctance on the part of surgeons regarding the administration of analgesics in patients with undifferentiated abdominal pain in the emergency situation [19]. Others have shown that the more experienced surgeons or physicians are even less liberal in the use of analgesics, particularly narcotics, for these patients [18].

\section{Conclusion}

This study shows that withholding analgesics from patients with acute abdominal pain is prevalent among the Nigerian doctors studied. This practice is not influenced significantly by specialty or length of years of post-qualification experience. The needed long-term measures are capacity building and training of doctors in the specialty of emergency medicine with the ultimate aim of establishing this specialty in the country like it is in the developed world, which would improve the overall management of all patients presenting acutely, including those with acute abdominal pain. In the interim, the organization of seminars and training programs on acute care is necessary to improve patient care.

\section{References}

1. Silen W (1987) Cope's Early Diagnosis of Acute Abdomen, 17th edn. Oxford University Press, New York

2. Pace S, Burke TF (1996) Intravenous morphine for early pain relief in patients with acute abdominal pain. Acad Emerg Med 3: 1086-1092

3. Vermeulen B, Morabia A, Unger PF et al (1999) Acute appendicitis: Influence of early pain relief on the accuracy of clinical and US findings in the decision to operate - a randomized trial. Radiology 210:639-643

4. Thomas SH, Silen W, Cheema F et al (2003) Effects of morphine analgesia on diagnostic accuracy in emergency department patients with abdominal pain: a prospective, randomized trial. J Am Coll Surg. 196:18-31

5. Mchale PM, LoVecchio F (2001) Narcotic analgesia in acute abdomen-A review of prospective trials. European Journal of Emergency Medicine 8:131-136

6. Manterola C, Astudillo P, Losada H, Pineda V, Sanhueza A, Vial M. Analgesia in patients with acute abdominal pain. Cochrane Database of Systematic Reviews 2007, Issue 3. Art. No.: CD005660. DOI: 10.1002/14651858. CD005660.pub2.

7. Gallagher EJ, Esses D, Lee C et al (2006) Randomized clinical trial of morphine in acute abdominal pain. Ann Emerg Med 48:150-60

8. Attard AR, Corlett MJ, Kidner NJ et al (1992) Safety of early pain relief for acute abdominal pain. BMJ 305:554-6

9. Silen W (2000) Cope's Early Diagnosis of the Acute Abdomen. Oxford, New York, p 5

10. Shabbir J, Ridgway PF, Lynch K et al (2004) Administration of analgesia for acute abdominal pain sufferers in the accident and emergency setting. Eur J Emerg Med 11:309-12

11. Wolfe JM, Lein DY, Lenkoski K et al (2000) Analgesic administration to patients with an acute abdomen: a survey of emergency medicine physicians. Am J Emerg Med 18:250-253 
12. Goldman RD, Crum D, Bromberg R et al (2006) Analgesia administration for acute abdominal pain in the paediatric emergency department. Pediatr Emerg Care 22:18-21

13. Green RS, Kabani A, Dostmohamed $\mathrm{H}$ et al (2004) Analgesic use in children with acute abdominal pain. Pediatr Emerg Care 20:725-9

14. Lee JS, Stiell IG, Shapiro S, Quinn JV (1996) Physician's attitude toward opioid analgesic use in acute abdominal pain [abstract]. Acad Emerg Med. 3:494

15. Vessey W, Siriwardena A (1998) Informed consent in patients with acute abdominal pain. Br J Surg 85:1278-80

16. Kay R, Siriwardena AK (2001) The process of informed consent for urgent abdominal surgery. J Med Ethics 27:157-61

17. Andress D, Pace S (1992) Cognitive capacity after intravenous morphine administration. Ann Emerg Med 21:1047

18. Zimmerman O, Halpern P (2004) Opinion survey of analgesia for abdominal pain in Israeli emergency departments. Isr Med Assoc.J 6(11):681-685 Nov

19. Graber MA, Ely JW, Clarke S et al (1999) Informed consent and general surgeons attitudes towards the use of pain medication in the acute abdomen. Am. J. Emerg. Med 17:113-116

Dr. B. A. Ayoade is a general surgeon with interest in trauma and acute care. He was trained in Nigeria and holds the Fellowship of the
West African College of Surgeons and Royal College of Surgeons in Ireland. He is currently a Senior Lecturer in Surgery at the Department of Surgery, Olabisi Onabanjo University, and Consultant Surgeon to Olabisi Onabanjo University Teaching Hospital, Sagamu, Nigeria.

Dr. A. O. Tade is a general surgeon and holds the Fellowship of the West African College of Surgeons and Royal College of Surgeons. Currently, he is Senior Lecturer in Surgery at the Department of Surgery, Olabisi Onabanjo University, and Consultant Surgeon to Olabisi Onabanjo University Teaching Hospital, Sagamu.

Dr. B. A. Salami is a general surgeon and holds the Fellowship of the West African College of Surgeons and National Postgraduate Medical College in Surgery. Currently, he is a Senior Lecturer in Surgery at the Department of Surgery, Olabisi Onabanjo University, and Consultant Surgeon to Olabisi Onabanjo University Teaching Hospital, Sagamu.

Dr. O. Oladapo is a gynecologist and obstetrician and holds the Fellowship of the West African College of Surgeons and National Postgraduate Medical College in Obstetrics and Gynecology. Currently, he is a Lecturer and Consultant Gynecologist and Obstetrician at University College Hospital, Ibadan, Nigeria. 